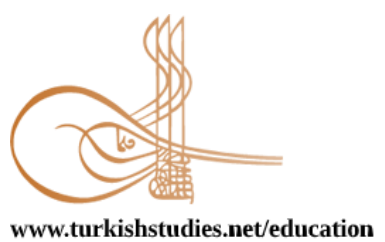

www.turkishstudies.net/education
Turkish Studies - Educational Sciences

eISSN: 2667-5609

Research Article / Araștırma Makalesi

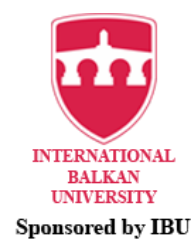

Sponsored by IBU

\title{
Mobil Anlık Mesajlaşma Uygulamaları Üzerinden Üniversite Öğrencilerinin Yabancı Dil Gelişimlerinin Desteklenmesi*
}

\author{
Supporting Foreign Language Development of University Students Through Mobile Instant \\ Messaging Applications
}

\author{
Feyzi Kaysi* $^{* *}$
}

\begin{abstract}
Applications on the smartphones that university students frequently use are actively involved in their learning processes. These applications can be used to support students' foreign language development processes in the form of extracurricular activities. The aim of this study is to examine the changes in foreign language development as a result of supporting university students through instant messaging applications. In addition, the views of some of these participants on this process were included in the study. The study was designed as mixed pattern. Quantitative and qualitative methods are used. In the assessments of the quantitative data, paired sample t-test analyzes were performed over the pretest and posttest success scores of 31 participants. Qualitative data were collected through face-to-face interviews with seven participants through a semistructured interview form. Qualitative data were analyzed via content analysis. When the findings of the study are examined, it is understood that instant messaging application is effective. It was determined that the foreign language development of the participants increased significantly in the six-week period. It was also determined that, with the process, the participants started to be more effective in the lessons due to the development of vocational foreign language. In this context, it was stated that the participants' interest in the course increased. It is understood that this situation has positive effects on the self-confidence and motivation levels of the participants. However, it was stated that some participants were bored with the application because they had low interest in foreign languages. Among the suggestions of the study, there is a suggestion that a similar study can be conducted for a longer period of time, and that the participants' foreign language development, changes in the interest and motivation levels of the course can be followed.
\end{abstract}

Structured Abstract: Technological devices have started to be among the most important requirements of daily life. It increases the interaction of users with these devices over time. This result has an impact on the emergence of applications that allow greater interaction over time. In particular, portable devices are more preferred because they give users more flexibility. Smartphones, which are the most common among these devices, are used extensively by university youth today. Since mobile devices are used by students for multiple purposes, they are at the center of students' lives. Applications on the smartphones that university students

\footnotetext{
* Çalışma verileri 2019 yılında toplanmış ve 2020 yılında yayına hazırlanmıştır. Bu nedenle çalışmanın etik kurul onayı yoktur.

*** Dr. Öğr.Üyesi, İstanbul Üniversitesi-Cerrahpaşa, Teknik Bilimler Meslek Yüksekokulu, Elektronik ve Otomasyon Bölümü

Asst. Prof. Dr. Istanbul University-Cerrahpasa, Vocational School of Technical Sciences, Department of Electronics and Automation

ORCID 0000-0001-6681-4574

fkaysi@istanbul.edu.tr

Cite as/ Atıf: Kaysi, F. (2020). Mobil anlık mesajlaşma uygulamaları üzerinden üniversite öğrencilerinin yabancı dil gelişimlerinin desteklenmesi. Turkish Studies - Education, 15(3), 2271-2284. https://dx.doi.org/10.29228/TurkishStudies.41661

Received/Geliş: 07 February/Şubat 2020

Accepted/Kabul: 24 June/Haziran 2020

Copyright (C) INTAC LTD, Turkey

Checked by plagiarism software

Published/Yayın: 25 June/Haziran 2020

CC BY-NC 4.0
} 
frequently use are actively involved in their learning processes. These applications can be used to support students' foreign language development processes in the form of extracurricular activities. The aim of this study is to examine the changes in foreign language development as a result of supporting university students through instant messaging applications. In addition, the views of some of these participants on this process were included in the study.

The study was designed as mixed pattern. Quantitative and qualitative methods are used. In the assessments of the quantitative data, paired sample t-test analyzes were performed over the pretest and posttest success scores of 31 participants. Qualitative data were collected through face-to-face interviews with seven participants through a semi-structured interview form. Qualitative data were analyzed via content analysis. Lastly, in order to support the findings of the study, all instant messaging group messages were included in the study.

In this study, which was carried out to support the vocational foreign language development of university students, the results of the instant mobile messaging application with unsuccessful students were discussed. In obtaining these results, the pre-test and post-test analyzes applied to the participants and the interviews with the participants in the group were taken into consideration. In addition, all participants' translations within the group were examined. As a result of the analysis of the pre-test and post-tests received from the participants, a significant difference emerged in favor of the post-test. It was concluded that the significance value of the meaningfulness that occurred due to the use of instant mobile messaging application between the pre-test and post-test was also high. With this result, it can be stated that supporting students with low levels of foreign language success with extracurricular activities has positive results. In addition, the most important reason for this positive result can stated as students have instant mobile messaging applications that they can access and communicate whenever they want. Because students use smartphones intensely, so they can access new notifications constantly. In other words, it can be stated that the foreign language development of students is positively affected with the advantages of mobile instant messaging application.

Previous experiences make new learning easier. In this way, better translations have emerged over time. The most important indicator of this has been revealed in the statements of some participants who think they are unsuccessful and inadequate. These participants stated that after the six-week experience in the instant mobile application group, they started to translate better and their vocabulary increased in this process. In this regard, they stated that they started to sit in the front rows in order to participate in the class instead of sitting in the back rows of the class. From this point of view, it can be interpreted that the increase in the experience and foreign language skills of the participants also increased their self-confidence. Accordingly, it is understood that the participants who have developed vocational foreign language skills through the application have increased their participation to the lessons over time. Participants' expressing that their interest in the course increased, was among the positive results of the study. Along with these positive results, some participants' negative statements about the instant mobile messaging group also attracted attention. These negative situations were expressed as long six-week application period, starting to get bored with time and no interest in foreign language.

Significant results have been obtained in this study conducted to support the foreign language development of university students. According to these results, sending positive texts with extracurricular activity in the instant mobile messaging group had positive effects on foreign language development. These results are supported by both face-to-face interviews and texts in the messaging group. The self-confidence of students who have increased their foreign language skills has increased. As a result, they tried to increase their participation in the class by sitting in the front rows instead of sitting in the back rows. Over time, foreign language comprehension levels have increased. They also evaluated and compared the translations with their peers in order to increase the quality of their translations and then sent them to messaging groups. Finally, the fact that the translation texts are related to the programs and professions in which they are studying has also positively affected the interests of the students.

Among the suggestions of the study, there is a suggestion that a similar study can be conducted for a longer period of time, and that the participants' foreign language development, changes in the interest and motivation levels of the course can be followed.

Keywords: Educational Sciences, Mobile instant messaging application, WhatsApp, Foreign language development, University students 
Öz: Üniversite öğrencilerinin sıklıkla kullandıkları akıllı telefonlarındaki uygulamalar öğrenme süreçlerinde etkin bir şekilde yer almaktadır. Bu uygulamalar ders dışı faaliyet şeklinde öğrencilerin yabancı dil gelişim süreçlerine destek olmak amacıyla kullanılabilir. Bu çalışmanın amacı üniversite öğrencilerinin anlık mesajlaşma uygulamaları üzerinden desteklenmesi sonucunda yabancı dil gelişimlerindeki değişimlerin incelenmesidir. Ayrıca bu öğrencilerin bu sürece yönelik görüşleri de bu kapsamda çalışmaya dahil edilmiştir. Çalışma nicel ve nitel yöntemler kullanıldığı için karma desendedir. Nicel verilerin değerlendirilmesinde 31 katılımcının ön-test ve son-test başarı puanları üzerinden bağımlı gruplar t-testi analizleri yapılmıştır. Nitel veriler yarı-yapılandırılmış görüşme formu üzerinden yedi katılımcıyla yapılan yüz-yüze görüşmelerle toplanmıştır. Nitel veriler içerik analizine tabi tutulmuştur. Çalışmanın bulguları incelendiğinde, anlık mesajlaşma uygulamasının etkili olduğu anlaşılmaktadır. Altı haftalık süreçte katılımcıların yabancı dil gelişimlerinin anlamlı düzeyde arttığı belirlenmiştir. Ayrıca katılımcıların süreçle birlikte, mesleki yabancı dil gelişimine bağlı olarak derslerde daha etkin olmaya başladıkları gözlenmiştir. Bu kapsamda katılımcıların derse yönelik ilgilerinin arttığı ifade edilmiştir. Bu durumun katılımcıların özgüvenlerinin ve motivasyon düzeylerinin artmasına olumlu etkileri olduğu anlaşılmaktadır. Bununla birlikte bazı katılımcıların yabancı dile karşı ilgisi olmaması nedeniyle uygulamadan sıkıldığı ifade edilmiş̧ir. Çalışmanın önerileri arasında, benzer bir çalışmanın daha uzun süreli yapılması sağlanarak, katılımcıların yabancı dil gelişimleri, derse yönelik ilgi ve motivasyon düzeylerindeki değişimlerin takip edilebileceği önerisi yer almaktadır.

Anahtar Kelimeler: Eğitim Bilimleri, Mobil anlık mesajlaşma uygulaması, WhatsApp, Yabancı dil gelişimi, Üniversite öğrencileri

\section{Giriş}

Teknolojik cihazlar günlük yaşamın en önemli gereksinimleri arasında yer almaya başlamıştır. Kullanıcıların zamanla bu cihazlarla olan etkileşimleri artmaktadır. Zamanla daha fazla etkileşime imkan tanıyan uygulamaların ortaya çıkmasında bu sonucun etkisi vardır. Özellikle taşınabilir özellikteki cihazlar, kullanıcılara daha fazla esneklik tanıdığı için daha fazla tercih edilmektedir. Bu cihazlar arasında kullanımı en yaygın olan akıllı telefonlar günümüz üniversite gençleri tarafından yoğun bir şekilde kullanılmaktadır. Mobil cihazlar öğrenciler tarafından çok amaçlı kullanıldığı için öğrencilerin hayatının merkezinde yer almaktadır (Deshpande, 2015). Teknolojinin gelişimi ile bir bilgisayarın küçülerek ve gelişerek bir elde taşınması durumuna erişen cep telefonları, içerisinde birçok bilginin taşınmasına olanak sağlamıştır. Son on yıldan beri, sosyal ağ sitelerinin üniversite öğrencileri arasında kullanımı dünya çapında hızla artmakta ve gençlerin önemli bir parçası haline gelmiştir (Isha ve Sharma, 2018). Bu gelişmenin en önemli nedeni akıllı telefonların sayılarının ve kullanım oranlarının artmış olması görülebilir. Akıllı telefonlar sahip oldukları özellikler ile insanların yaşamını kolaylaştırmaktadır (Günal ve Pekçetin, 2019). Cep telefonu kullanan bireyler arasında ise üniversite öğrencileri geniş bir grubu oluşturmaktadır (Uzgüren, Şengür ve Yiğit, 2013). Üniversite kampüslerinde veya sinıflarda akıllı telefonlar, günümüz üniversite öğrencilerinin sürekli bir arkadaşı haline gelmiştir (Reese Bomhold, 2013). Aynı zamanda üniversite öğrencilerinin mobil cihazlardaki internet kullanımları da artmaktadır (Dahlstrom, Dziuban ve Walker, 2012).

Önceleri kişiler arası iletişim çoğunlukla yüz-yüze iletişimle sağlanıyorken, günümüzde teknolojiler sayesinde farklı ortamlarda iletişim kanalları yer bulmuştur. Özellikle çevrimiçi ortamlar bu iletişim kanallarının başını çekmektedir. Üniversiteler de bu durumun farkında olarak çeşitli çevrimiçi uygulamalar geliştirmektedir (Aydemir, Kaysi ve Gülseçen, 2018). Öğretmenler ve öğrenciler, çalışma ve eğitim amaçlı her yerde bulunan sosyal medya kanallarını kullanmanın bazı yararları olduğu ve genel olarak olumlu olduğu konusunda hemfikirdirler (Asterhan \& Rosenberg, 2015). Bu bakımdan, özellikle akıllı telefonlar insanlara eşsiz bir deneyim sunmakta ve her zaman ve her yerde çevrimiçi olmalarını sağlamaktadır (Alan ve Eyuboğlu, 2012; Kaysi ve Aydemir, 2019). $\mathrm{Bu}$ süreçlerde mobil mesajlaşma uygulamaları ile, bireylerin iletişimleri süreklilik arz etmeye başlar hale gelmiştir. İnternet sosyal ağları, insanların metin, resim, ses ve video dosyalarını kolayca paylaşmalarını sağlayan her yerde bulunan uygulamalar haline gelmiştir (Rosenfeld vd., 2018). 
WhatsApp, bireylerin genellikle doğrudan bir veya birkaç arkadaşıyla iletişim kurmak için kullandığı ve bu nedenle özel bir iletişim kanalını temsil eden bir uygulama şeklinde ifade edilmiştir (Karapanos, Teixeira ve Gouveia, 2016). Ayrıca WhatsApp'ın üniversite öğrencileri arasında popüler olduğuna dair çalışmalar bulunmaktadır (Ahad ve Lim 2014; Cetinkaya, 2017; Devi ve Tevera, 2014; Gasaymeh, 2017; Yeboah ve Ewur, 2014). Öğrencilerin WhatsApp iletişimini tercih etme nedenleri arasında kolay erişim, topluluk oluşturma yeteneği ve iletişim biçimi gibi avantajlar yer almaktadır (Rosenberg ve Asterhan, 2018).

Anlık mesajlaşma uygulamalarının öğrenme süreçlerinde kullanımı ile ilgili araştırma sonuçları dikkat çekicidir. Whatsapp, eğitim faaliyetlerinin kurulmasına yönelik bir platform olarak kullanılabilmektedir (Yin, 2016). Çünkü WhatsApp'ın öğrenme aracı olarak kullanılmasının hem öğrenciler hem de eğitmenler için yararlı olduğu sonucuna ulaşılmıştır (Malecela, 2016). Diğer bir ifade ile bu tür anlık mesajlaşma uygulamaları öğrenme etkinliklerinde kullanılabilmektedir (Rosenberg ve Asterhan, 2018). Çünkü anlık mesajlaşma platformlarının eğitimde kullanılması durumunda, bu uygulamaların öğrenmeyi arttırma potansiyeli olduğu tespit edilmiştir (Smit, 2012). Öğrenciler, WhatsApp'ın faydalı bir öğrenme aracı olabileceği konusunda hemfikirdir (So, 2016). Son olarak WhatsApp, lisans öğrencilerine, arkadaşları ile günlük iletişiminin yanı sıra, derslerle ilgili bilgileri tartışma ve paylaşma imkanı sağlar (Ahad ve Lim, 2014). Bu durum öğrenciler tarafından bu uygulamanın en çok tercih edilme nedeni olarak da ifade edilebilir. Anlık mesajlaşma uygulamalarının sahip olduğu grup özelliği ile, bire-bir görüşmelerin yanında çoklu görüşmeler de gerçekleştirilebilmektedir. Bu gruplarda dersler, öğretim elemanları, sınavlar, ulaşım, iletişim vb. konularda topluluk olarak görüşmeler yapılmaktadır. Sınıf WhatsApp grupları, okulla ilgili konular için merkezi bir iletişim kanalı haline gelmiştir (Rosenberg ve Asterhan, 2018). Öğrenciler ders duyuruları yayınlar, ders arkadaşlarıyla dersler hakkında fikirlerini tartışırlar, ders almış öğrencilerden yardım isterler, derslerle ilgili konu ve kaynaklara linkler verirler, ders çalışmaya yönelik gruplar oluştururlar, ders arkadaşlarıyla toplantılar düzenler ve ders çalışma saatlerini düzenlerler (Joicy ve Sornam, 2018).

Eğitimdeki niteliğin artması amaciyla mobil uygulamalar geliştirilmektedir. Mobil uygulamalar öğrenciler tarafından; eğlenceli öğrenme ortamı sunma ve ders başarısına olumlu katkı sunma özelliği barındırdığı belirtilmiştir (Durak ve Yılmaz, 2019). Öğrenciler mobil teknolojilerin öğrenim süreçlerinde kullanımını etkileşimi eğlenceli ve motive edici bulmaktadırlar (Mohammed Ali ve Rashad Ali Bin-Hady, 2019; Shih, Lee ve Cheng, 2015). Akıllı telefonlarda dil öğrenme uygulamaları öğrencilerin yabancı dil yeterlilikleri üzerinde olumlu sonuçlar ortaya çıkarmıştır (Lee ve Kim, 2013). Bu tür uygulamalardaki iletişim, geleneksel öğrenme yönteminden farklı olarak, özellikle genç bireyler için çekici olmayan yabancı dil öğrenimini cazip hale getirerek öğrenme sürecine fayda sağlar (Plana ve diğ., 2013). Benzer bir şekilde, mobil destekli öğrenme ortamları öğrencilerin kelime dağarcı ̆̆ı açısından başarıyı arttırdığı (Agca ve Özdemir, 2013) ve öğrencilerin yabancı dildeki kelimeleri daha iyi bir şekilde akılda tutabildikleri görülmüştür (Thornton ve Houser, 2003). WhatsApp'ın öğrenciler arasında popüler bir iletişim platformu olması yabancı dil öğrenimine olumlu etki etme potansiyeline sahiptir (Alabsi ve Alghamdi, 2019). WhatsApp gibi araçlarla, öğrencilerin yabancı dil öğrenimleri büyük ölçüde iyileşmiştir (Alfaki ve Alharthy, 2014). Bu bakımdan WhatsApp'ın yabancı dil olarak İngilizce ögrenmede olumlu bir etkiye sahip olduğu belirlenmiştir (Kaid Mohammed Ali ve Rashad Ali Bin-Hady, 2019). Yabancı dil öğreniminde öğretim elemanlarının öğrencileri desteklemesi ihtiyacı bulunmaktadır (Finkbeiner, Knierim, Smasal ve Ludwig, 2012). Bu nedenle bu tür uygulamalarda öğretim elemanlarının olması, beklenen sonuçların elde edilmesini kolaylaştırabilir. Anlık mesajlaşma uygulamaları ile öğrencilerin daha iyi cümle yapıları kurmaları ve etkili kelime seçimi yapmaları sağlanabilir (Andujar, 2016; Hani, 2014). Ayrıca öğrencilerin bu uygulamaları kullanmaları sınıftaki motivasyon, memnuniyet ve istekli olma düzeylerini arttırmaktadır (Fattah, 2015; Winet, 2016). Öğrencilere anlık mesajlaşma grubu 
üzerinden yapılan öğrenme etkinlikleri sonucunda öğrenmelerin olumlu etkilendiği, samimi bir etkileşim sağlandığı ve eğlenceli öğrenmelerin gerçekleştiği ortaya çıkmıştır (Setyowati, 2019).

Avrupa Dil Portföyü (ADP), Diller için Avrupa Ortak Başvuru Çerçevesi: Öğrenme, Öğretme, Değerlendirme belgesinde üç düzeyde olacak şekilde yabancı dil becerilerini sınıflamıştır (Council of Europe, 2001). Bu düzeyler (A) temel kullanıcı, (B) bağımsız kullanıcı ve (C) yetkin kullanıcı şeklindedir. Bu sınıflar çerçevesinde bireylerin yabancı dil beceri düzeyleri ifade edilmiştir. ADP, Avrupa Konseyi Dil Politikası Bölümü tarafından geliştirilen bir dil öğrenme ve raporlama aracıdır (Şentürk, 2017a). Aynı zamanda ADP, bireylerin hedef dili öğrenme sürecinde deneyimlerini ve dilsel başarılarını kaydetmelerini sağlayan bir öz-değerlendirme aracı sunmaktadır (Mirici, 2015). Türkiye Yükseköğretim Yeterlilikler Çerçevesi, İletişim ve Sosyal Yetkinlik başlığında 5. Düzeyde yer alan Meslek Yüksekokul (MYO) Programlarındaki öğrenciler için "Bir yabanc1 dili en az Avrupa Dil Portföyü A2 Genel Düzeyinde kullanarak kullanarak alanındaki bilgileri izleyebilme ve meslektaşları ile iletişim kurabilme" ibaresi geçmektedir (Yükseköğretim Kurulu, 2010). Bu ifade ile, MYO programlarındaki öğrencilerin yabancı dil becerilerinin nasıl olması gerektiği belirtilmiştir. Günümüzde dil öğrenimi her zamankinden daha önemli bir hale gelmiştir. Bu bağlamda, farklı dillere sahip bireyler arasında iletişim, karşılıklı etkileşim için hayati bir öneme sahiptir (Şentürk, 2017b). Bu kapsamda üniversite öğrencilerinin mesleki yabancı dil becerilerinin beklenen düzeyde olması ihtiyacı ortaya çıkmaktadır. Çünkü mesleğin icra edilmesinde ve bireylerin meslektaşlarıyla etkileşiminde yabancı dil becerisi önemli bir ihtiyaç haline gelmiştir. Bu kapsamda ders içi ve ders dışı etkinliklerle, öğrencilerin yabancı dil becerilerinin geliştirilmesi gerekmektedir. Öğrencilerin yabancı dil ilgi ve becerilerini arttırmak amacıyla etkileşimli anlık mobil mesajlaşma uygulamaları kullanılabilir. Bu çalıșmanın amacı yabancı dil başarı düzeyi düşük öğrencilerin anlık mesajlaşma uygulamaları üzerinden desteklenmesi sonucunda yabancı dil geliş̧imlerindeki değişimlerin incelenmesidir. Ayrıca bu öğrencilerin bu sürece yönelik görüşleri de bu kapsamda çalışmaya dahil edilmiştir. Bu sayede, mobil cihazlar üzerinden yapılan bu etkinliğin öğrencilere katkı durumu ve öğrencilerin algıları belirlenebilir.

\section{Yöntem}

Çalışmada nicel ve nitel veriler kullanıldığı için araştırma karma desenle gerçekleştirilmiştir. Dabbs (1982), nicel yaklaşımı temel olarak bazı şeylerin miktarı ve nitel yaklaşımı şeylerin doğası için gerekli olduğunu belirtmiştir. Güçlü bir karma desen çalışmasında nitel ve nicel verilerin birbirini destekleyici mahiyette olması önemlidir (Tashakkori ve Creswell, 2007). Çalışmanın ilk aşamasında nicel tekniklerle veriler toplanmıştır. Bu kapsamda katılımcıların mesleki yabancı dil gelişimleri takip edilmiştir. Bu süreçte ders dış1 etkinlik olarak, belirlenen gruptaki katılımcılara anlık mesajlaşma uygulaması üzerinden İngilizce metinler gönderilmiştir. Gruptaki katılımcıların bu metinleri Türkçeye çevirmeleri talep edilmiştir. Çalışmanın ikinci aşamasında ise, yedi katılımcıdan yüz-yüze görüşme yöntemi ile birinci aşamadaki deneyimleri alınmıştır. Bu kapsamda nitel veri toplama teknikleri ile çalışmanın ikinci aşaması tamamlanmıştır. Durum çalışması deseni ile çalışma yürütülmüştür. Durum çalışması, olayları tanımlamak ve açıklamak amacıyla belirli bir olayın sistematik olarak araştırması şeklinde tanımlanmıştır (Bromley, 1990). Bu kapsamda yarıyapılandırılmış form ile katılımcılarla yapılan yüz-yüze görüşmelerdeki veriler çalışmaya dahil edilmiştir. Patton (1987) görüşme yöntemini, olayların bireylerin bakış açılarıyla anlaşılması ve kavranması şeklinde ifade etmiştir. Son olarak, anlık mesajlaşma uygulamasındaki tüm grup görüşmeleri katılımcı izinleri doğrultusunda çalışmaya dahil edilmiştir.

\section{Katılımcilar}

Çalışmanın tüm katılımcıları İstanbul'daki bir devlet üniversitesinde öğrenim görmekte olan meslek yüksekokulu öğrencilerinden oluşmaktadır. Çalışma iki aşamada planlandığı için, birinci aşamada deney grupları üzerinden katılımcıların mesleki yabancı dil gelişimleri takip edilmiştir. Çalışmanın ikinci aşamasındaki katılımcılarla, anlık mesajlaşma uygulamalarının yabancı dil 
gelişimleri üzerindeki etkisine yönelik görüşleri toplanmıştır. Bu bakımdan ikinci aşamadaki bulguların, birinci aşamada elde edilen sonuçlarla karşılaştırılmaları da amaçlanmıştır.

Çalışmanın ilk aşamasında anlık mobil mesajlaşma uygulaması grubunda 31 katılımcı yer almaktadır. Deney grubundaki katılımcıların hepsi anlık mesajlaşma uygulaması üzerinden oluşturulan mesleki yabancı dil grubuna gönüllü olarak dahil olmuşlardır. Bu katılımcılarla altı hafta boyunca hafta içi dersin olduğu gün hariç her gün, önceden belirlenmiş metinler paylaşılmıştır. Paylaşılan metinler katılımcıların meslekleriyle doğrudan ilgili ve ADP A2 düzeyindeki yabancı dil düzeylerine uygun olacak şekilde belirlenmiştir. Belirlenen tüm metinler için iki uzmandan görüş alınmıştır. Bu uzmanlardan birisi metinleri mesleki içerik açısından, diğeri ise yabancı dil düzeyi açısından kontrol etmiştir. Katılımcılarla paylaşılan metinlerin, katılımcılar tarafından Türkçeye çevrilmeleri beklenmiştir. Ayrıca bu metin içerisinde öğrendikleri kelimeleri de geri-bildirimde bildirim şeklinde vermeleri istenmiştir. Katılımcıların gönderdikleri tüm metinler kısa zamanda değerlendirilmiştir. Yapılan değerlendirmelerde çevirilerin (1) gönderilen İngilizce metne uyumluluğu ve (2) cümlelerin anlam bütünlükleri kontrol edilmiştir. Yapılan kontroller sonucunda uygun görülmeyen metinler, yeniden çeviri yapılmaları amacıyla katılımcılara geri gönderilmiştir. Katılımcıların çeviri programlarına metinleri olduğu gibi yapıştırıp, çabalarını en aza indirmenin önüne geçmek amacıyla, cümleler bazı yerlerde enter/kesme ile bölünmüştür. Bu sayede bu işlem ile cümlenin akıcılığına müdahale edilmemiştir. Fakat katılımcıların bu metni olduğu gibi çeviri programına atması halinde devrik ve anlamsız olması sağlanmıştır. Altı haftalık uygulama sonunda katılımcılara ön-teste denk olacak şekilde geliştirilen son-test uygulanmıştır. Ön-test ve son-testin geliştirilmesi süreçlerinde, daha önceden görüşleri alınan iki uzmandan tekrar faydalanılmıştır. Bu süreçte hazırlanan formlar uzmanlara sunularak mesleki program içeriğini yansıtması, ADP A2 yabancı dil düzeyine sahip olması ve testlerin birbirine dank yapıda olması değerlendirilmiştir. Katılımcıların bu süreçteki tüm çeviri metinleri de çalışmada değerlendirilen veriler arasına dahil edilmiştir.

Yüz-yüze görüşme yöntemine dahil edilen katılımcilar, gönüllülük ilkesine göre görüşlerini çalışmaya aktarmışlardır. Katılımcılar amaçlı örnekleme türlerinden ölçüt örnekleme göre belirlenmiştir. Bu kapsamda, (1) katılımcıların uygulamadan memnuniyet durumları ve (2) çeviri gönderme sayıları dikkate alınmıştır. Çalışmanın bu aşamasında görüş belirtmek isteyen potansiyel katılımcılar gerekli bilgilendirmeler yapıldıktan sonra planlamalar yapılmıştır. Bu planlamalarda; katılımcıların müsait oldukları zamanlar kaydedilmiştir. Katılımcılara aydınlatılmış onam formu imzalatılmış ve verilerin toplanması aşamasına geçilmiştir. Aydınlatılııı̧ onam formunda, katılımcıları doğrudan veya dolaylı olarak işaret edebilecek hiçbir verinin çalışmada kullanılmayacağı açıkça belirtilmiştir. Ayrıca sorulacak sorular için, katılımcıların istemedikleri hiçbir soruya cevap vermek zorunda olmadıkları da ifade edilmiştir. Son olarak katılımcıların istedikleri zaman görüşmeyi bitirebilecekleri de kendilerine aktarılmıştır.

\section{Verilerin Toplanması}

Çalışmanın ilk aşamasındaki deney grub verileri ön-test ve son-test ile toplanmıştır. Altı haftalık anlık mesajlaşma uygulaması sonunda, uzman görüşü alınarak hazırlanmış testlerin birbirine denk olması sağlanmıştır. Bu süreçte katılımcıların yabancı dil gelişimlerindeki değişimler takip edilmiştir. Katılımcılardan toplanan ön-test ve son-test sonuçları ile bağımlı gruplar t-testi analizleri gerçekleştirilmiştir. Ayrıca altı haftalık çalışma süresince, katılımcıların gönderdikleri tüm çeviriler anlık mesajlaşma uygulamasından bilgisayar ortamına aktarılmıştır. Çalışmanın nitel boyutundaki veriler, yarı-yapılandırılmış görüşme formu üzerinden yapılan görüşmelerle toplanmıştır. $\mathrm{Bu}$ formların amacı, katılımcıların standart sorulara verdikleri cevapların ötesine geçmektir (Berg, 2012). Tüm katılımcılarla yapılan görüşmeler ses kayıt cihazı ile kaydedilmiştir. Görüşmeler kaydedilmeden önce katılımcılardan izin alınmıştır. Elde edilen ses kayıtları, araştırmacı tarafından dijital ortama aktarılmıştır. Sonraki aşamada ses kayıtları transkript edilmiştir. Elde edilen bu 
metinler katılımcıların teyit etmeleri amacıyla belirttikleri e-posta adreslerine gönderilmiştir. Bu epostada, katılımcıların tüm metni okumaları ve değişiklik (ekleme, silme veya düzenleme) yapmak istemeleri halinde yapabilecekleri belirtilmiştir. Ayrıca araştırmacıya gönderilecek son metinler üzerinden analizlerin yapılacağı da ifade edilmiştir. Katılımcıların teyitleri sonrasındaki metinler üzerinden içerik analizi çalışmalarına geçilmiştir.

\section{Verilerin Analizi}

Çalışmanın ilk veri kaynağı olarak ön-test ve son-test başarı testlerindeki sonuçlar incelenmiştir. Çalışmanın nicel kısmında veri analizi için bağımlı gruplar t-testi kullanılmıştır. Çalışmanın ikinci veri kaynağı analizinde ise yapılan görüşmelerin kayıtları kullanılmıştır. Bu kayıtların içerik analizine tabi tutulması ile çalışmadaki kodlar ve temalar belirlenmiştir. Nitel çalışmalardaki metinlerde yer alan kelimelerin daha az sayıdaki içerik kategorisine indirilmesine içerik analizi denilmektedir (Creswell, 2013). Elde edilen tema ve kodların sunumunda, bazı katılımcı görüşleri doğrudan alıntı şeklinde çalışmaya eklenmiştir. Çalışmanın üçüncü veri kaynağı olarak, anlık mobil mesajlaşma uygulamasındaki tüm mesajlar incelenmiştir. Yapılan incelemelerde haftalık katılımcılardan gelen çeviri sayılarındaki değişim dikkate alınmıştır. Çalışmalarda verilerin birbirini desteklemesi ve daha doğru sonuçlara ulaşılması amacıyla veri çeşitliliği önem arz etmektedir. Bu veri çeşitliliğini sağlamanın yollarından birisi de üçgenlemedir. Üçgenleme ile veri çeşitliliği sağlandığ 1 takdirde çalışmalardaki sınırlılık ve yanlılık riski en aza iner ve geçerlik en üst düzeye çıkar (Maxwell, 1996). Bu çalışmada verileri kullanılan başarı testleri, görüşme ve doküman incelemesi ile üçgenlemenin sağlanması amaçlanmıştır.

\section{Bulgular}

Mesleki yabancı dil düzeyi düşük öğrencilerin, yabancı dil becerisi gelişimlerini desteklemek amacıyla anlık mobil mesajlaşma uygulaması üzerinden altı haftalık bir çalışma yürütülmüştür. Bu çalışma kapsamında, ön-test ve son-test başarı testleri, yüz-yüze görüşmeler ve mesajlaşma grubundaki katılımcı çevirileri incelenmiştir. Yapılan incelemelerin elde edilen bulgular bu başlıkta sunulmuştur. Elde edilen ilk bulgular, katılımcıların altı haftalık çalışma öncesi ve sonrasına yönelik gelişimlerini gösteren ön-test ve son-test analiz sonuçlarıdır. Bu analiz sonuçları Tablo 1'de verilmiştir.

Tablo 1: Katılımcıların Ön-Test Son-Test Bağımlı Gruplar T-testi Sonuçları

\begin{tabular}{lccrcccc}
\hline & $\overline{\boldsymbol{x}}$ & $\mathbf{n}$ & \multicolumn{1}{c}{ ss } & $\mathbf{t}$ & $\mathbf{s d}$ & $\mathbf{p}$ & $\mathbf{d}$ \\
\hline Ön-test & 26,58 & 31 & 8,45 & $-8,13$ & 30 &, 00 & 1,46 \\
Son-test & 39,97 & 31 & 10,88 & & & & \\
\hline
\end{tabular}

Tablo 1 incelendiğinde, katılımcıların altı haftalık yabancı dil puanlarında ortaya çıkan değişim ve bu değişimin anlamlılık durumu görülmektedir. Bağımlı örneklem t-testi sonucunda, katılımcıların ön-test ve son-test sonuçları arasında yüksek düzeyde etki değeri (eta squared $=1,46$ ) olan bir anlamlılık belirlenmiştir. Bu anlamlılık uygulama sonucunda ortaya çıkan başarı puanlarını kapsayan son-test lehine gerçekleşmiştir. Yani çalışma grubunda yapılan anlık mesajlaşma etkinliklerinin grubun başarısına olumlu yönde etki ettiği görülmektedir.

Çalışmanın bir diğer veri kaynağı arasında yer alan, katılımcı çeviri metinleri incelenmiştir. Yapılan bu incelemede, katılımcılara gönderilen metinlerde haftalık değişim olduğu görülebilmektedir. Bu değişme yönelik veriler Tablo 2'de verilmiştir. 
Tablo 2: Katılımcıların Haftalık Çeviri Sayıları

\begin{tabular}{lcc}
\hline Hafta & Ceviri Sayısı & Tekil Katılımcı Sayısı \\
\hline 1. Hafta & 85 & 31 \\
2. Hafta & 58 & 23 \\
3. Hafta & 76 & 27 \\
4. Hafta & 52 & 19 \\
5. Hafta & 47 & 18 \\
6. Hafta & 61 & 21 \\
\hline
\end{tabular}

Tablo 2'de, altı hafta boyunca haftada dört gün gönderilen metinler için, katılımcıların çeviri sayıları görülebilmektedir. Bu veriler incelendiğinde en yüksek yoğunluktaki çeviri ve katılımcı sayılarının ilk haftada yer aldığı görülmektedir. Bunun yanında en az yoğunluk beşinci haftada tespit edilmiştir. Tekil katılımcı sayısı, ilgili haftada gönderilen dört metin için tüm kullanıcılar arasında en az bir çeviri gönderen katılımcı sayısını ifade etmek amacıyla belirtilmiştir.

Çalışmanın birinci aşamasında elde edilen nicel veri bulgularını desteklemek amacıyla, katılımcılarla yüz-yüze görüşmeler yapılmıştır. Bu görüşmeler sonrasında yapılan analizlerde (1) Anlık Mobil Mesajlaşma Grubu Uygulaması ve (2) Yabancı Dil Gelişimi temaları elde edilmiştir. Bu temalara ait kodlar ve bazı katılımcı görüşleri doğrudan alıntı şeklinde aşağıda verilmiştir.

\section{Anlık Mobil Mesajlaşma Grubu Uygulaması}

Katılımcı ifadeleri üzerinden, uygulamanın yabancı dil gelişimi üzerindeki etkisi incelenmiştir. $\mathrm{Bu}$ kapsamda katılımcıların gönderilen metinleri çevirmeye yönelik sorumluluk hissettikleri anlaşılmaktadır. $\mathrm{Bu}$ nedenle çevirilerin ilk firsatta ve kontrolleri sağlanarak gönderilmeye çalışıldığ ifade edilmiştir. Bu kontrollerde, katılımcıların kendi çevirilerini diğer diğer katılımcılarla kıyasladıkları belirtilmiştir. Anlık mesaj uygulaması ile etkin bir şekilde sürece dahil olduklarını ve bunun yabancı dil geliş̧imlerine olumlu şekilde etkisi olduğu dile getirilmiştir. Ayrıca gün içerisinde müsait olmadıkları durumlarda, çeviri yapmayı unutmamak için gelen mesajları bildirim durumunda tuttukları da anlaşılmaktadır. Temaya yönelik bazı katılımcı görüşleri doğrudan alıntı şeklinde aşağıda verilmiştir.

Uygulamanın verimliliği yüksek bence. Cümle çevirmelerinde ve kelime haznemizin gelişmesinde büyük bir katkısı var. Grup içinde gelen metinleri ilk firsatta okumaya ve anlamaya çalışlyorum. Gün bitmeden de çevirisini ve yeni öğrendiğim kelimeleri ben de grupta paylaşıyorum.

Kelime haznemizi geliştirmede oldukça etkili bir yöntem olduğunu düşünüyorum. Çevirilerle uğraştıkça ileride yaptığım çevirileri daha kolay ve bazı paragrafları yardım almadan yapabilmeye başladım.

Müsaitsem çeviriyi hemen yapmaya çalışlyorum değilsem bildirimde tutup (unutmamak için) daha sonra çeviri yapıyorum.

Son olarak, katılımcılar tamamladıkları çevirilerini uygulama üzerinden göndermeden önce, akranlarıyla çevirilerini değerlendirdiklerini ve kıyaslama yaptıktan sonra çevirilerini gönderdiklerini ifade etmiştir. Bu sayede çevirilerini daha iyi duruma getirmeyi amaçladıklarını belirtmişlerdir. Bu bulguların yanında bazı katılımcılar, bu uygulamanın uzun sürmesi nedeniyle sıkıldığını ve İngilizceyi sevmeyen kişiler için sıkıcı olduğunu dile getirmişlerdir.

Gruptaki çevirilerle yeni kelimeler öğrenmek. Arkadaşlarımızla çeviriler hakkında tartı̧̧arak İngilizcemizi geliş̧tirmemize imkan sağllyor.

Bir süre sonra sıkmaya başliyor. Faydası olan bir uygulama ama bir süredir devam etmesi sıktı açıkçası. Yorulduğumu ve sıkıldığımı düşünüyorum uygulamanın iyi olması bir yana ben çok sikıldım uygulamalardan. 


\section{Yabancı Dil Gelişimi}

Katılımcılara gönderilen metinlerin mesleki içerikte olması katılımcıların dikkatlerini çekmiştir. Metinlere yönelik yapılan çevirilerin iş hayatındaki etkisi ve bu sürecin mesleki gelişimlerine olan olumlu etkileri belirtilmiştir. İş hayatında karşılaşabilecekleri teknik ve mesleki metinlerin anlaşılmasında kolaylık sağlayacağı da dile getirilmiştir. Bu kapsamda katılımcılar, metinlerin çevirilerinin yapılması ile mesleki yabancı dil becerilerinin olumlu şekilde etkilendiğini ifade etmişlerdir. Zamanla daha fazla deneyime sahip oldukları için çevirilerde daha özenli oldukları da dile getirilmiştir. Bu sayede katılımcıların derse yönelik ilgilerinin arttığı anlaşılmaktadır. Temaya yönelik bazı katılımcı görüşleri doğrudan alıntı şeklinde aşağıda verilmiştir.

Yeni teknik kelimeler öğreniyorum ve bu teknik kelimeler ilerideki iş hayatımda karşıma çıkabilir. İ̧̧ hayatımda da karşıma çıkan metinler olduğundan cümleleri daha kolay ayrıştırabiliyorum.

Ingilizce ve Türkçe arasında gramer farkı olduğu için metinleri çevirirken devrik cümle kurmamaya özen gösteriyorum.

Zamanla uygulama üzerinden gönderilen mesleki içerikteki metin sonucunda katılımcıların çeviri yapma deneyimlerinin ve kelime haznelerinin arttığ ifade edilmiştir. Bu durumun katılımcıların derslerdeki davranışlarına da etkileri olduğu anlaşılmaktadır. Bazı katılımcılar mesleki yabancı dil dersinde daha etkin olmaya başladıklarını ifade etmişlerdir. Bunun en önemli nedeni olarak da, uygulama üzerinden yapılan çevirilerin mesleki yabancı dil gelişimleri üzerinde olumlu etkisinin olduğu dile getirilmiştir. Bu katılımcılar derse yönelik ilgilerinin arttığını ve derse katılım göstermek amacıyla ön sıralarda oturmaya başladıklarını belirtmişlerdir.

Ne kadar zorlansam da bir şeyler öğreniyorum. Daha önceden gördüğ̈̈m kelimeler tanıdık geliyor ve zamanla basitleşiyor. Artık okuduğum cümleleri anlayabiliyorum.

Bu uygulamayı kullanmak aslında bizim yararımıza. Bu sayede derse olan ilgim artmaya başladl. Artık çevirileri isteyerek yapıyorum. Önceden çevirileri anlamadı̆̆ım için arkalarda otururdum. Şimdi çevirmek için en önde oturuyorum.

\section{Sonuç, Tartışma ve Öneriler}

Üniversite öğrencilerinin mesleki yabancı dil gelişimlerini desteklemek amacıyla yapılmış bu çalışmada, başarısız durumdaki öğrencilerle gerçekleştirilen anlık mobil mesaj uygulaması sonuçları ele alınmıştır. Bu sonuçların elde edilmesinde öncelikli olarak katılımcılara uygulanan öntest ve son-test analizleri ve grup içerisinde yer alan katılımcılarla yapılan görüşmeler dikkate alınmıştır. Bunlara ek olarak, katılımcıların tamamının grup içerisindeki çevirileri incelenmiştir. Katılımcılardan alınan ön-test ve son-testlerin analizi sonucunda son-test lehine anlamlı farklılik ortaya çıkmıştır. Ön-test ve son-test arasında anlık mobil mesajlaşma uygulaması kullanımına bağlı olarak ortaya çıkan anlamlılı̆̆ın etki değerinin de yüksek olduğu (Cohen, 1988) sonucuna ulaşılmıştır. Öğrencilere yönelik anlık mesajlaşma grubu üzerinden yapılan öğrenme etkinliklerinde öğrenmelerin olumlu etkilendiği, samimi bir etkileşim ortamının sağlandığı ve eğlenceli öğrenmelerin gerçekleştiği ortaya çıkmıştır (Setyowati, 2019). Ayrıca, yabancı dil başarı düzeyi düşük öğrencilerin ders dışı etkinliklerle desteklenmesinin olumlu sonuçları olduğu ifade edilebilir. Mobil uygulamalarla ders etkinliklerinin desteklenmesi, ders başarısına olumlu katkılar sağlamaktadır (Durak ve Yılmaz, 2019). Ayrıca bu olumlu sonucun en önemli nedeni olarak, öğrencilerin sürekli erişebildikleri ve istedikleri zaman iletişime geçebilecekleri anlık mobil mesajlaşma uygulamasına sahip olmaları gösterilebilir. Öğrenciler WhatsApp iletişimini kolay erişim sunması, topluluk oluşturma yeteneği ve sürekli iletişim nedenleriyle tercih etmektedirler (Rosenberg ve Asterhan, 2018). Çünkü öğrenciler yoğun bir şekilde akıllı telefon kullanmakta ve bu sayede de sürekli olarak gelen yeni bildirimlere erişebilmektedirler. Diğer bir ifadeyle, mobil anlık mesajlaşma uygulaması avantajlarıyla öğrencilerin yabancı dil gelişimlerinin olumlu şekilde 
etkilendiği belirtilebilir. Akıllı telefonlarda yabancı dil öğrenme uygulamaları ile öğrencilere yönelik olumlu sonuçlar ortaya çıkabilmektedir (Lee ve Kim, 2013). Bu tür uygulamalardaki iletişim, geleneksel öğrenme yönteminden farklı olarak, özellikle genç bireyler için çekici olmayan yabancı dil öğrenimini cazip hale getirerek öğrenme sürecine fayda sağlar (Plana ve diğ., 2013).

Önceki deneyimler yeni öğrenmeleri kolaylaştırır. Bu sayede zamanla daha iyi çeviriler ortaya çıkmıştır. Mobil destekli öğrenme ortamlarının, öğrencilerin kelime dağarcıklarını arttırmaya yardımcı olduğu (Agca ve Özdemir, 2013) ve yabancı dildeki kelimeleri daha iyi bir şekilde akılda tutmalarını sağladığı belirlenmiştir (Thornton ve Houser, 2003; Genç ve Aydemir, 2015). Bunun en önemli göstergesi, başarısız ve yetersiz olduğunu düşünen bazı katılımcıların ifadelerinde ortaya çıkmıştır. Bu katılımcılar anlık mobil uygulama grubundaki altı haftalık deneyimleri sonunda daha iyi çeviri yapmaya başladıklarını ve bu süreçte kelime haznelerinin arttığını ifade etmişlerdir. Anlık mesajlaşma uygulamaları ile öğrencilerin daha iyi cümle yapıları kurmaları ve etkili kelime seçimi yapmaları sağlanabilir (Andujar, 2016; Hani, 2014). Bu doğrultuda, deneyimleri artan öğrencilerin sınıfın arka sıralarında oturmak yerine, derse katılmak amacıyla ön sıralarda oturmaya başladıkları belirlenmiştir. Buradan hareketle, katılımcıların deneyimlerinin ve yabancı dil becerilerinin artması, özgüvenlerini de arttırmıştır şeklinde bir yorum yapılabilir. Çünkü öğrencilerin bu uygulamaları kullanmaları sınıftaki motivasyon, memnuniyet ve istekli olma düzeylerini arttırmaktadır (Fattah, 2015; Winet, 2016). Bu doğrultuda, uygulama üzerinden mesleki yabanc1 dil becerisi gelişen katılımcıların zamanla derslere daha fazla katılım sağladıkları anlaşılmaktadır. Katılımcıların derse yönelik ilgilerinin arttığını ifade etmeleri çalışmanın olumlu sonuçları arasında yer almıştır.

$\mathrm{Bu}$ olumlu sonuçlarla birlikte, bazı katılımcıların anlık mobil mesajlaşma grubuna yönelik olumsuz ifadeleri de dikkat çekmiştir. Bu olumsuz durumlar, altı haftalık uygulama süresinin uzun olması, zamanla sıkılmaya başlamaları ve yabancı dile karşı ilgi duyulmaması şeklinde ifade edilmiştir. Yabancı dil öğreniminde öğretim elemanlarının öğrencileri desteklemesi ihtiyacı bulunmaktadır (Finkbeiner ve diğ., 2012). Bu nedenle bu tür uygulamalarda öğretim elemanlarının olması, beklenen sonuçların elde edilmesini kolaylaştırabilir. Ayrıca uygulamadan memnun kalmayan ve sıkılan öğrencilere erişilerek yaşanan sorunlar çözülebilir.

Üniversite öğrencilerinin yabancı dil gelişimlerini desteklemek amacıyla yapılan bu çalışmada önemli sonuçlar elde edilmiştir. Bu sonuçlara göre, anlık mobil mesajlaşma grubunda ders dışı etkinlikle mesleki amaçlı metinlerin gönderilmesinin yabancı dil gelişimine olumlu etkileri ortaya çıkmıştır. Bu sonuçlar hem yüz-yüze görüşmelerde hem de mesajlaşma grubundaki metinlerle desteklenmektedir. Yabanc1 dil beceri düzeyi artan öğrencilerin özgüvenleri artmıştır. Bunun neticesinde sınıfta arka sıralarda oturmak yerine ön siralarda oturarak dersteki katılımlarını arttırmaya çalışmışlardır. Zamanla yabancı dil anlama düzeyleri artmıştır. Ayrıca yaptıkları çevirilerin niteliğini arttırmak amacıyla akranlarıyla çevirileri değerlendirmiş, karşılaştırmış ve daha sonra mesajlaşma gruplarına göndermişlerdir. Son olarak, çeviri metinlerinin öğrenim gördükleri program ve meslekleriyle ilgili olması da öğrencilerin ilgilerini olumlu şekilde etkilemiştir.

Çalışmadan elde edilen sonuçlar göz önünde bulundurularak aşağıdaki öneriler sıralanabilir.

- Çalışma başarı düzeyi düşük öğrencilerle yürütülmüştür. Benzer bir çalışma başarı düzeyi daha iyi durumda olan gruplar için de yapilabilir. Bu gruplardaki değişim ve bu çalışmadan elde edilen sonuçlar karşılaştırılabilir.

- Süreç altı hafta sürdürülmüştür. Daha uzun süreli çalışmalarda, elde edilen sonuçlar, bu çalışmadaki sonuçlarla karşılaştırılabilir. Daha uzun süreçlerdeki çalışmalarda, katılımcıların motivasyon değişimleri gözlemlenebilir.

- Yabancı dil beceri gelişimi için, öğrencilerin bu tür anlık mesajlaşma uygulamalarında kendi buldukları metinleri çevirmeleri sağlanabilir. Bu sayede öğrencilerin ilgileri arttırılabilir.

- Öğrencilerin konuşma becerilerinin geliştirilmesi amacıyla anlık mobil mesajlaşma uygulamasında yabancı dildeki metinleri seslendirmeleri ve bunu kaydetmeleri sağlanabilir. 
$\mathrm{Bu}$ ses kayıtlarının gruptaki katılımcıların izinleri doğrultusunda, değerlendiriciye gönderilmesi ile öğrencilerin konuşma becerilerinin gelişimi de takip edilebilir.

\section{Kaynakça}

Agca, R. K., \& Özdemir, S. (2013). Foreign language vocabulary learning with mobile technologies. Procedia-Social and Behavioral Sciences, 83, 781-785. https://doi.org/10.1016/j.sbspro.2013.06.147

Ahad, A. D., \& Lim, S. M. A. (2014). Convenience or nuisance?: The 'WhatsApp' dilemma. Procedia-Social and Behavioral Sciences, 155, 189-196. https://doi.org/10.1016/j.sbspro.2014.10.278

Alabsi, K. M., \& Alghamdi, F.M.A. (2019). Students' Opinions on the Functions and Usefulness of Communication on WhatsApp in the EFL Higher Education Context. Arab World English Journal, Special Issue 1: Application of Global ELT Practices in Saudi Arabia. 129-144. https://dx.doi.org/10.24093/awej/elt1.10

Alan, A. E., \& Eyuboglu, E. (January 2012). Generation Y Consumers in Turkey: Are They Really Social Media Nerds or Pretend To Be? 11th international marketing trends congress 1921th. Venice-Italy.

Alfaki, I. M. \& Alharthy, K. (2014). Towards a Digital World: Using Social Networks to Promote Learner's Language. American International Journal of Contemporary Research, 4(10), $105-114$.

Andujar, A. (2016). Benefits of mobile instant messaging to develop ESL writing. System, 62, 6376. https://doi.org/10.1016/j.system.2016.07.004

Asterhan, C. S., \& Rosenberg, H. (2015). The promise, reality and dilemmas of secondary school teacher-student interactions in Facebook: The teacher perspective. Computers \& Education, 85, 134-148. https://doi.org/10.1016/j.compedu.2015.02.003

Aydemir, E., Kaysi, F., \& Gülseçen, S. (2018). Üniversite Mobil Uygulamalarının İçerik Açısından Değerlendirilmesi, S. Gülseçen, Yönetim Bilişim Sistemlerinde Gündem (145-157) İstanbul: Çağlayan Yayınevi.

Berg, L. B., \& Lune, H. (2012). Qualitative Research Methods for Social Sciences ( $8^{\text {th }}$ ed.). New Jersey: Pearson Education Inc.

Bromley, D. B. (1990). Academic contributions to psychological counseling: A philosophy of science for the study of individual cases. Counseling Psychology Quarterly 3(3), 299-307. https://doi.org/10.1080/09515079008254261

Cetinkaya, L. (2017). The Impact of Whatsapp Use on Success in Education Process. International Review of Research in Open and Distributed Learning, 18(7). https://doi.org/10.1016/ j.compedu.2013.08.012

Cohen, J. (1988). Statistical power analysis for the behavioral sciences, 2nd edition. Lawrence Erlbaum Associates.

Council of Europe (2001). Common European Framework of Reference for Languages: Learning, Teaching, Assessment (CEFR). Erişim <https://www.coe.int/en/web/common-europeanframework-reference-languages/>

Creswell, J. W. (2013). Qualitative inquiry and research design: Choosing among five approaches (3rd ed.). Thousand Oaks, CA: Sage Publications. 
Dabbs, J. M., Jr. (1982). Making things visible. In J. Van Maanen (Ed.), Varieties of Qualitative Research. Beverly Hills, Sage.

Dahlstrom, E., Dziuban, C. \& Walker, J. (2012). ECAR Study of Undergraduate Students and Information Technology 2012. EDUCAUSE Center for Applied Research, Louisville, CO.

Deshpande, A. (2015). Mobile Addiction and Associated Factors Amongst Youth. Indian Journal of Mental Health, 2(3), 244-248. https://doi.org/10.30877/ijmh.2.3.2015.244-248

Devi, T. S., \& Tevera, S. (2014). Use of social networking site in the University of Swaziland by the health science students: A Case study. Jounal of Information Management, 1(1), 19-26.

Durak, A., \& Yılmaz, F. G. K. (2019). Artırılmış Gerçekliğin Eğitsel Uygulamaları Üzerine Ortaokul Öğrencilerinin Görüşleri. Abant İzzet Baysal Üniversitesi Ĕ̆itim Fakültesi Dergisi, 19(2), 468-481. https://doi.org/10.17240/aibuefd.2019.19.46660-425148

Fattah, S. F. E. S. A. (2015). The effectiveness of using WhatsApp messenger as one of mobile learning techniques to develop students' writing skills. Journal of Education and Practice, 6(32), 115-127.

Finkbeiner, C., Knierim, M., Smasal, M. \& Ludwig, P. H. (2012). Self-regulated cooperative EFL reading tasks: students' strategy use and teachers' support. Language Awareness, 21(1), 5783. https://doi.org/10.1080/09658416.2011.639892

Gasaymeh, A. M. M. (2017). University Students Use of WhatsApp and their Perceptions Regarding its Possible Integration into their Education. Global Journal of Computer Science and Technology, 17(1), 1-10.

Genç, Z., \& Aydemir, E. (2015). An Alternative Evaluation: Online Puzzle As a Course-End Activity. Interactive Technology and Smart Education, 12(3): 169-182. https://doi.org/10.1108/itse-04-2015-0008

Günal, A., \& Pekçetin, S. (2019). Üniversite Öğrencilerinde Akıllı Telefon Bağımlılı̆̆ı İle Servikal Bölge-Üst Ekstremite Ağrısı Arasındaki İlişki. Sürekli Tıp Ĕgitimi Dergisi, 28(2): 114-119. https://doi.org/10.17942/sted.381207

Hani, N. A. B. (2014). The impact of WhatsApp group's utilization on EFL students' vocabulary writing amelioration. International Journal of University Teaching and Faculty Development, 5(2), 73-87.

Isha, S. K., \& Sharma, S. (2018). A Review on Perception of Usage-"WhatsApp". International Journal of Scientific Research in Computer Science, Engineering and Information Technology, 3(1), 1382-1393.

Joicy, A. J., \& Sornam, S. A. (2018). Perception of WhatsApp Usage among Students of College of Excellence: A Case Study. Indian Journal of Information Sources and Services, 8(1), 73-78.

Kaid Mohammed Ali, J., \& Rashad Ali Bin-Hady, W. (2019). A Study of EFL Students' attitudes, motivation and anxiety towards WhatsApp as a Language Learning Tool. Arab World English Journal (AWEJ) Special Issue on CALL, (5), 289-298. https://doi.org/10.24093/awej/call5.19

Karapanos, E., Teixeira, P., \& Gouveia, R. (2016). Need fulfillment and experiences on social media: A case on Facebook and WhatsApp. Computers in Human Behavior, 55, 888-897. https://doi.org/10.1016/j.chb.2015.10.015 
Kaysi, F., \& Aydemir, E. (2019). Üniversite Öğrencilerinin Sınıf İçi Mesajlaşma Gruplarındaki Mesaj İçeriklerinin İncelenmesi. 13. Uluslararası Bilgisayar ve Öğretim Teknolojileri Sempozyumu.

Lee, K. J., \& Kim, J. E. (2013). A mobile-based learning tool to improve writing skills of EFL learners. Procedia-Social and Behavioral Sciences, 106, 112-119. https://doi.org/10.1016/j.sbspro.2013.12.014

Malecela, I. O. (2016). Usage of Whatsapp among Postgraduate Students of Kulliyyah of Education, International Islamic University Malaysia. International Journal of Advanced Engineering Research and Science, 3(10), 126-137. https://dx.doi.org/10.22161/ijaers/310.21

Maxwell, A. J. (1996). Qualitative Research Design: An Interactive Approach. London: Sage Publication.

Mirici, I. H. (2015). Contemporary ELT practices across Europe and in Turkey. International Journal of Language Academy, 3(4), 1-8. http://dx.doi.org/10.18033/ijla.333

Patton, M. Q. (1987). How to use qualitative methods in evaluation (No. 4). Sage Publications.

Plana, M. G. C., Escofet, M. I. G., Figueras, I. T., Gimeno, A., Appel, C., \& Hopkins, J. (2013). Improving learners' reading skills through instant short messages: A sample study using WhatsApp. 4th WorldCALL Conference, Glasgow, 10-13 July 2013.

Reese Bomhold, C. (2013). Educational use of smart phone technology: A survey of mobile phone application use by undergraduate university students. Program, 47(4), 424-436. https://doi.org/10.1108/prog-01-2013-0003

Rosenberg, H., \& Asterhan, C. S. C. (2018). "WhatsApp, Teacher?" - Student perspectives on teacher-student WhatsApp interactions in secondary schools. Journal of Information Technology Education: Research, 17, 205- 226. https://doi.org/10.28945/4081

Rosenfeld, A., Sina, S., Sarne, D., Avidov, O., \& Kraus, S. (2018). WhatsApp usage patterns and prediction of demographic characteristics without access to message content. Demographic Research, 39, 647-670. https://doi.org/10.4054/demres.2018.39.22

Setyowati, Y. (2019, July). Let's Listen Through WhatsApp: An energizing listening exercise in EFL Class. Journal of Physics: Conference Series, 1179(1), 12-52). https://doi.org/10.1088/1742$6596 / 1179 / 1 / 012052$

Shih, R. C., Lee, C., \& Cheng, T. F. (2015). Effects of English spelling learning experience through a mobile LINE App for college students. Procedia-Social and Behavioral Sciences, 174, 2634-2638. https://doi.org/10.1016/j.sbspro.2015.01.945

Smit, I. (2012). WhatsApp with BlackBerry; Can messengers (BBM) be MXit? In Proceedings of the 14th annual conference on world wide web applications. Cape Town, South Africa: Cape Peninsula University of Technology.

So, S. (2016). Mobile instant messaging support for teaching and learning in higher education. The Internet and Higher Education, 31, 32-42. https://doi.org/10.1016/j.iheduc.2016.06.001

Şentürk, B. (2017a). The Power of Self-Assessment in Foreign Language Education. Karaelmas Eğitim Bilimleri Dergisi, 5(2), 352-359.

Şentürk, B. (2017b). Experience in Implementing the European Language Portfolio (ELP) with Turkish Adult Learners. Karaelmas Eğitim Bilimleri Dergisi, 5(2), 383-394. 
Tashakkori, A., \& Creswell, J. W. (2007). Exploring the nature of research questions in mixed methods research. Journal of Mixed Methods Research, 1(3), 207-211. https://doi.org/10.1177/1558689807302814

Thornton, P., \& Houser, C. (2005). Using mobile phones in English education in Japan. Journal of Computer Assisted Learning, 21(3), 217-228. https://doi.org/10.1111/j.13652729.2005.00129.x

Uzgören, E., Şengür, M., \& Yiğit, Ü. (2013). Üniversite öğrencilerinin cep telefonu talebinde israfa yönelik davranışlarının analizi-Dumlupınar Üniversitesi öğrencilerine yönelik bir uygulama. Süleyman Demirel Üniversitesi İktisadi ve İdari Bilimler Fakültesi Dergisi, 18(1): 29-44.

Winet, D. (2016). Mobile Instant Messaging in the ESL Writing Class. The Electronic Journal for English as a Second Language, 20(3), 1-6.

Yeboah, J., \& Ewur, G. D. (2014). The impact of whatsApp messenger usage on students performance in Tertiary Institutions in Ghana. Journal of Education and practice, 5(6), 157164.

Yin, L. C. (2016). Adoption of WhatsApp instant messaging among students in Ipoh Higher Education Institutions. Retrieved, 1(25), 2018.

Yükseköğretim Kurulu (2010). Türkiye Yükseköğretim Yeterlilikler Çerçevesi (TYYÇ): 5. Düzey (Önlisans Eğitimi) Yeterlilikleri. Erişim <http://tyyc.yok.gov.tr/?pid=32>. 